\title{
As inundações de 1967 na região de Lisboa Uma catástrofe com diferentes leituras
}

Francisco da Silva Costa ${ }^{1}$, costafs@geografia.uminho.pt; Miguel Cardina ${ }^{2}$; António Avelino Batista Vieira ${ }^{1}$

\section{RESUMO}

Na noite de 25 para 26 de Novembro de 1967, chuvas intensas abateram-se sobre a área da Grande Lisboa (Lisboa, Loures, Odivelas, Vila Franca de Xira e Alenquer), com as inundações a causarem um elevado número de mortos, milhares de desalojados e inúmeras habitações destruídas. Apesar dos impressionantes impactes então originados, o episódio permanece pouco evocado. As abordagens teóricas e académicas ao assunto têm mais em conta o fenómeno meteorológico e os efeitos produzidos no território e menos as consequências sociais e a observação dos impactos de natureza política. Com base na consulta e análise de fontes documentais de diferentes proveniências, tentamos reconstituir alguns episódios sociais e políticos que marcaram o pós-crise das inundações de 1967, na região de Lisboa.

Palavras chave: Lisboa, 1967, inundações, censura, solidariedade.

\section{Flooding in Lisbon, Portugal in 1967. A disaster with different readings.}

\begin{abstract}
On the nights of 25 and 26 November 1967, heavy rains swept over the area of Lisbon (Lisboa, Loures, Odivelas, Vila Franca de Xira and Alenquer), with flooding causing a high number of deaths, thousands of homeless and countless homes destroyed. Despite the impacts originated the episode remains poorly evoked. The theoretical and academic approaches to the subject have focused more on the weather phenomenon and the effects produced in the territory and less on the social consequences and the observation of the impacts of a political nature. Based on consultation and analysis of hundreds of documentary sources, we have tried to document some social and political events that marked the post-flood crisis in 1967 in the Lisbon region.
\end{abstract}

Keyterms: Lisbon, 1967, floods, censorship, solidarity.

Recibido el 30 de mayo de 2016; aceptado el 17 de julio de 2016.

Departamento de Geografia e CEGOT, Universidade do Minho, Campus de Azurém, 4800 Guimarães.

2 Centro de Estudos Sociais da Universidade de Coimbra, Colégio de S. Jerónimo, Largo de D. Dinis, 3000-995 Coimbra. 


\section{INTRODUÇÃO}

A Região de Lisboa conheceu uma forte pressão urbana, especialmente a partir da década de 1960, traduzida, entre outros aspetos, pelo grande aumento da área construída e, dentro desta, das áreas urbanas de génese ilegal (AUGI). O desordenamento do território daí resultante refletiu-se, não só no agravamento da perigosidade potencial das cheias, mas também no incremento da vulnerabilidade decorrente da ocupação indevida dos leitos de cheia e, por vezes, dos leitos menores dos cursos de água (DUARTE et al. 2007).

O caso mais dramático deste tipo de atuação das águas em meio urbano conhecido em Portugal foi o da região de Lisboa, na noite de 25 para 26 de Novembro de 1967, que Fernando Rebelo define como uma das três grandes catástrofes verificadas em Portugal no último milénio, juntamente com o terremoto de 1755 em Lisboa e da aluvião de 1803 no Funchal (REBELO 2010). Particularmente afetada foi a área da Grande Lisboa (Lisboa, Loures, Odivelas, Vila Franca de Xira e Alenquer), com as inundações a causarem um elevado número de mortos, milhares de desalojados e inúmeras habitações destruídas.

Apesar dos impressionantes impactes que originou, o episódio permanece pouco evocado. A sua inscrição na memória pública é escassa e as abordagens teóricas e académicas ao assunto têm assentado mais na análise do fenómeno meteorológico e dos efeitos produzidos no território e menos as consequências sociais e na observação dos impactes de natureza política. A isto não será alheia a forma como o fenómeno foi tratado à época na imprensa. A este respeito, importa frisar que Portugal vivia então sob um regime ditatorial liderado por António de Oliveira Salazar, o Estado Novo, que impunha fortes limitações à liberdade de expressão e exercia a censura prévia aos jornais e a outras publicações periódicas.
Este trabalho exploratório procura identificar o modo como o fenómeno das inundações rápidas foi apropriado no campo político, produzindo-se leituras sobre o acontecimento que enveredaram por dois sentidos distintos. De um lado, o Estado e organizações de socorro próximas ou que colaboravam com o regime ditatorial focalizaram no impacto das causas naturais e acionaram, por isso, um discurso ancorado na fatalidade, no sofrimento e nos modos de minorá-lo. Por outro lado, as diferentes oposições avançaram com enquadramentos que se vincavam nas causas sociais que estiveram na base da destruição produzida pelas inundações. Num segundo momento, tomar-se-á como ponto de observação a atuação dos estudantes nas ações de auxílio.

Para este trabalho recorremos a um grande número de fontes documentais, quer primárias, quer secundárias. A investigação baseou-se sobretudo na consulta e análise de jornais nacionais e internacionais, revistas, blogues, artigos científicos, relatórios e correspondência, bem como fotografias e vídeos da época.

\section{A cheia rápida de 25 para 26 de Novembro de 1967 - uma abordagem do ponto de vista geográfico}

Do ponto de vista meteorológico, as inundações de Lisboa estão associadas às elevadas quedas pluviométricas que se fizeram sentir no dia 25 de novembro de 1967, resultado de um sistema depressionário formado na região do arquipélago da Madeira e que, desde 24 de Novembro, se começou a deslocar para nordeste, em direção à região de Lisboa (Fig. 1).

Aos efeitos desta depressão juntaram-se os de um sistema frontal que precedia uma massa de ar polar, de trajeto marítimo, transportada na circulação de um anticiclone centrado a norte dos Açores, deslocando-se com vento forte (AMARAL 1968; RAMOS $\&$ REIS 2001). 
Embora muito significativo, o quantitativo diário do dia 25 de novembro de 1967 não espelha de forma categórica a extrema intensidade das precipitações: das 19 horas à meia-noite, registaram-se $129 \mathrm{~mm}$ em Monte Estoril e $111 \mathrm{~mm}$ em S. Julião do Tojal (Fig. 2), o que equivale a uma intensidade média horária superior a 20 $\mathrm{mm}$, ao longo das 5 horas consideradas.
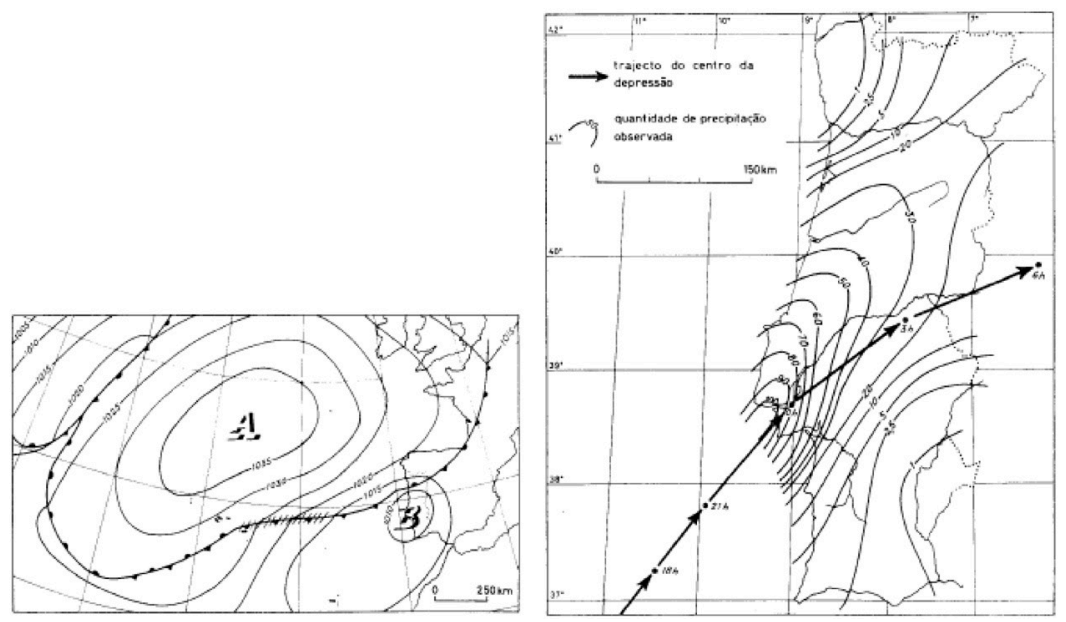

Fig. 1. Trajeto do centro de depressão e carta meteorológica de superfície referentes a 25-26 de novembro de 1967. Fonte: AMARAL 1968.

Fig. 1. Drive from the center of depression and surface weather map of 25-26 November, 1967. Source: AMARAL 1968.
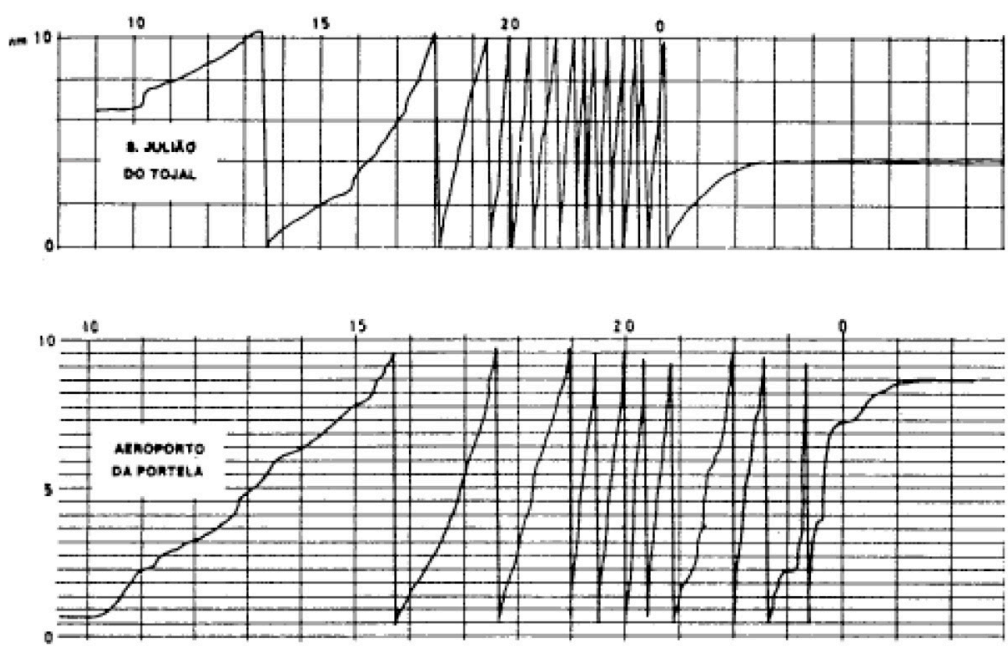

Fig. 2. Udograma do temporal de 25 de novembro de 1967: estações de São Julião do Tojal e Aeroporto da Portela. Fonte: LENCASTE e FRANCO 1984; RODRIGUES et al. 2011.

Fig. 2. Rainfall pluviogram, 25 November 1967: São Julião do Tojal and Portela airport metorological station. Source: LENCASTE \& FRANCO 1984; RODRIGUES et al. 2011. 
O valor da quantidade de precipitação equivaleu a $1 / 5$ do total anual, sendo que foram registrados valores de $88,6 \mathrm{~mm}$ na estação de Lisboa/Geofísico (Tabela 1) e
112,5 mm na estação de Lisboa/Tapada (AMARAL 1968; RAMOS \& REIS 2001; OLIVEIRA \& RAMOS 2001; ZÊZERE 2001 \& REBELO 2008).

tabela 1. Precipitação a 25 de Novembro de 1967. Fonte: Oliveira et al. (2002).

table 1. Rainfall, November 25, 1967. Source: Oliveira et al. (2002).

\begin{tabular}{|c|c|c|c|c|}
\hline Valor total $(1 / \mathrm{m} 2)$ & Duração (h) & $\begin{array}{l}\text { P. Máx. Horária (1/ } \\
\mathrm{m} 2 / \mathrm{h})\end{array}$ & $\begin{array}{l}\text { P. Máx. em relação ao } \\
\text { valor total }\end{array}$ & $\begin{array}{l}\text { P. Média Horária } \\
(1 / \mathrm{m} 2)\end{array}$ \\
\hline 88,6 & 14 & 26,1 & 29 & 6,3 \\
\hline
\end{tabular}

Embora o solo não se encontrasse saturado por chuvas antecedentes (ZÊZERE 1988), a intensidade da precipitação ultrapassou largamente a capacidade de infiltração dos terrenos (Tabela 2).

Tabela 2. Máximo de precipitação (Mm) registado na Cheia de 1967. Fonte: leal 2011.

Table 2. Rainfall maXimen (Mm) Recorded during flood, 1967. Source: Leal 2011.

\begin{tabular}{l|l|l}
\multicolumn{2}{l|}{ Máximo de precipitação (mm) } \\
\hline $\mathbf{1 h}$ & $6 \mathrm{~h}$ & $24 \mathrm{~h}$ \\
\hline $\mathbf{6 0 , 0}$ & 129,7 & 158,7 \\
\hline
\end{tabular}

A precipitação intensa levou a uma subida da água da ordem de 3 a 4 metros do rio Tejo e afluentes, o que inundou, segundo PAVIANI (1968), não só os pisos térreos, onde se localizava o comércio, mas também o piso superior, geralmente de habitação das áreas afetadas.

Outro impacto sentido esteve associado à erosão brutal dos leitos menores, sendo responsável por múltiplos deslizamentos/ desabamentos por erosão lateral nas margens das ribeiras e barrancos (FERREIRA \& ZÊZERE 1987; ZÊZERE et al. 2005; TRIGO et al. 2005).

As precipitações intensas abrangeram uma área relativamente extensa da região de Lisboa e vale do Tejo (Fig. 3), dando origem a 14 ocorrências de inundações e alagamentos (Colares, Oeiras, Cacém, Barcarena, Caxias, Cruz Quebrada, Lindaa-Pastora, Queluz, Bucelas, Loures, Odivelas, Póvoa de Santo Adrião, Olival Basto e Sacavém).

Apesar de se terem verificado ocorrências em quase toda a Península de Lisboa, foi nas bacias em torno da capital que se observaram mais problemas (Póvoa, Jamor e Barcarena), refletindo a maior vulnerabilidade dos seus elementos (LEAL 2011).

Embora as cheias rápidas constituam um fenómeno natural, as inundações consequentes e os prejuízos delas decorrentes são atribuíveis, em grande parte, a intervenções antrópicas desajustadas. De entre estas destacam-se a destruição do coberto vegetal natural e a recessão da 


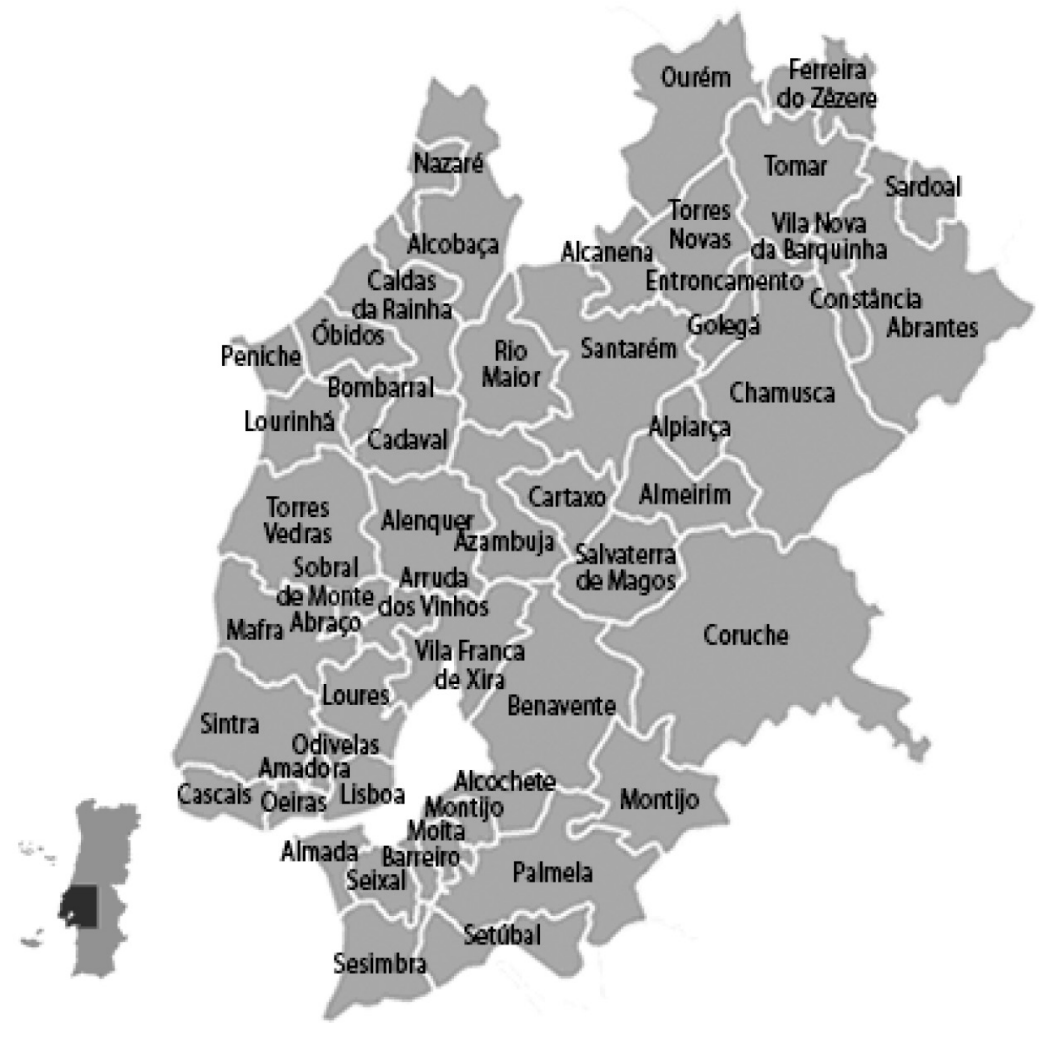

Fig. 3. Enquadramento administrativo de Lisboa e vale do Tejo. Fonte: https://lugaresmaisbelosdeportugal.wordpress.com/

Fig. 3. Administrative scheme of Lisboa and Vale do Tejo. Source: https://lugaresmaisbelosdeportugal.wordpress.com/

atividade agrícola nos últimos 40 anos, com o abandono das práticas tradicionais de conservação do solo (COUTINHO 1984); a expansão urbana, impermeabilização dos terrenos e drenagem em canais artificiais, responsáveis pela diminuição drástica da infiltração, aceleração do escoamento e redução do tempo de concentração das bacias hidrográficas (SEQUEIRA \& CASTRO 1987); a criação de estrangulamentos artificiais que constituem obstáculos ao escoamento, produzindo sobreelevações dos níveis de água a montante (QUINTELA 1984); a insuficiência e inadequação dos esgotos pluviais, que se mostram impotentes para drenar a água da chuva, contribuindo antes para aumentar a extensão das áreas inundadas, como aconteceu em a 25 de novembro de 1967 (ZÊZERE 2001).
Além de todos os impactes hidrológicos e geomorfológicos verificados durante e após a noite de 25 de Novembro de 1967, é também de referenciar um possível surto de leptospirose, ainda que não seja assinalado o número de infetados (SEAMAN et al. 1989; SIMÕES et al. 1969).

\section{A Imprensa e suas leituras perante a catástrofe}

As cheias de 1967 foram as mais catastróficas de todas, e são encaradas como algo que ficou marcado na história dos últimos 50 anos em Portugal, essencialmente pelo número de mortes contabilizadas (LEAL 2011).

Na primeira edição do dia 26 de Novembro, 
o título da primeira página do Diário de Lisboa refere "Chuva e morte: mais de 200 vítimas". Quatrocentos e vinte e sete mortos indicava o Diário de Notícias a 29 de Novembro de 1967, pouco antes da censura ter imposto a cessação da contagem pública (Diário de Notícias, 29/11/1967, n 13060). Os números oficiais falarão posteriormente de 462 vítimas mortais. A verdade é que ainda hoje não se sabe com rigor quantas pessoas morreram naquela tragédia. Sendo certo que os números apresentados pecam por defeito, também é certo que alguns dados indicados, dezenas de anos depois, podem pecar por excesso (cerca de 700 mortos, segundo RAMOS \& REIS, 2001). $\mathrm{Na}$ verdade, é plausível aceitar-se um número certamente superior a 500 mortos, atendendo a que uma semana após a tragédia ainda se retiravam alguns cadáveres das lamas acumuladas em Algés e se continuava a falar de vários desaparecidos que teriam sido arrastados até ao rio Tejo (REBELO 2008). Esse elemento explicará o facto das contagens de mortos se terem interrompido alguns dias após a tragédia, quando esses números ainda não estavam determinados e persistiam ações de auxílio no terreno. Nestas situações, e em especial quando os poderes públicos não querem revelar toda a dimensão da tragédia, a imprecisão é grande (COSTA et al. 2014).

Observando os jornais, é possível descortinar também modos distintos de reportar o tema. Jornais mais próximos do regime colocam a tónica no carácter inesperado da catástrofe e acentuam a onda de comoção gerada. O Diário da Manhã, por exemplo, refere a "cadeia de solidariedade humana (...) sem distinção de classes», que havia significado a «vitória do homem, que a natureza tinha esmagado". O Ministério de Interior divulgou uma nota oficiosa a propósito das trágicas ocorrências em que destaca ser "...a área atingida muito mais vasta e somente a violência do fenómeno de caráter excepcional, registrado nas horas dramáticas da noite de 25 para 26 de Novembro, pode explicar cabalmente a grandeza dos prejuízos causados..." (Diário de Lisboa, 1967). Numa leitura distinta, o Solidariedade Estudantil, boletim de estudantes organizados para prestar auxílio às populações sinistradas, apresentava estatísticas baseadas em dados do Serviço Meteorológico Nacional, mostrando que o máximo de pluviosidade havia ocorrido no Estoril, numa zona rica nos arredores da capital, apesar das mortes terem acontecido nos bairros de lata de Lisboa e arredores, assim como nas zonas pobres do Ribatejo (Solidariedade Estudantil, 1967, $\mathrm{n}^{\circ}$ 2). Também o Comércio do Funchal, particularmente lido pela juventude mais politizada, chamava abertamente a atenção para as causas sociais que haviam estado na base da catástrofe: "nós não diríamos: foram as cheias, foi a chuva. Talvez seja mais justo afirmar: foi a miséria, miséria que a nossa sociedade não neutralizou, quem provocou a maioria das mortes. Até na morte é triste ser-se miserável. Sobretudo quando se morre por o ser" (Comércio do Funchal, $\left.1967, \mathrm{n}^{\circ} 1963\right)$.

O tipo de linguagem usada era também reveladora: enquanto os jornais mais próximos do regime utilizavam uma linguagem marcada pela ideia de fatalidade, os jornais de oposição colocavam o acento tónico nas causas sociais que teriam estado na base da tragédia (Fig. 4). O Diário de Lisboa do dia 30 Novembro realça, na sua $1^{\text {a }}$ edição, que "o movimento de solidariedade que espontaneamente surgiu entre a população de todo o país", se traduziu "em múltiplas iniciativas", enquanto o Comércio do Funchal, dias mais tarde (a 10 de dezembro) questiona: "Na realidade, a água foi muita. Foi sem sombra de dúvida a grande culpada da catástrofe, mas se as «casas» (barracas) fossem verdadeiras casas teriam sido arrastadas pelas águas?".

Também crítico se mostrava o PCP (Partido Comunista Português), então na clandestinidade. Em Dezembro de 1967, 


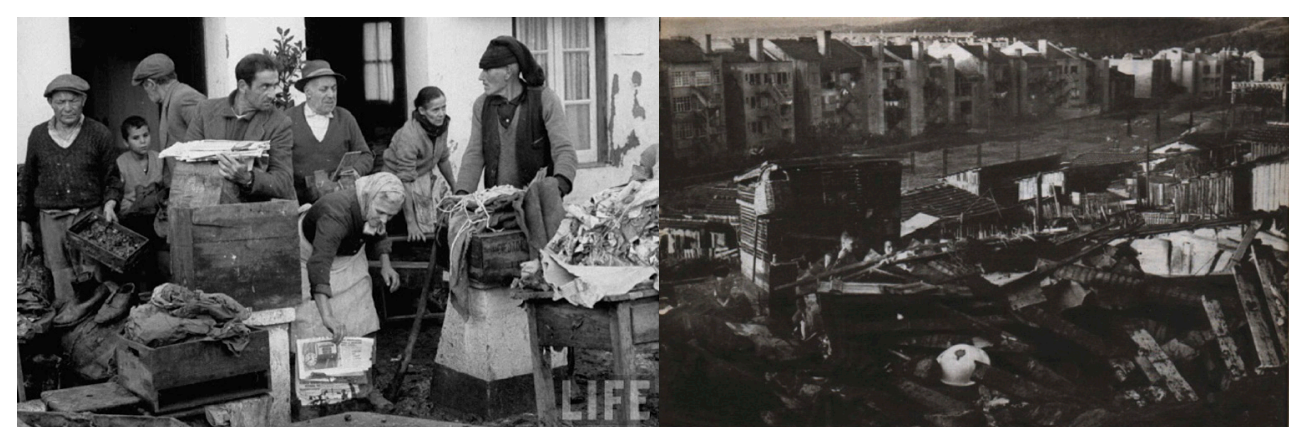

Fig. 4. Populações afetadas e bairros de lata destruídos pelas inundações de 1967 na região de Lisboa. Fonte: Século Ilustrado de 2 de Dezembro de 1967.

Fig. 4. People affected and tin neighborhood destroyed by flood, in 1967 in Lisboa region. Source: Século Ilustrado, December 2, 1967.

o Avante!, órgão do partido, concluía que "As inundações...não teriam originado semelhante tragédia se o governo se tivesse preocupado em resolver da habitação para os trabalhadores, se tivesse cuidado da regulamentação dos rios e da defesa das populações ribeirinhas, se tivesse tomado as medidas de emergência que as circunstâncias impunham...". E questiona “... porque não foram destruídos pelas chuvas diluvianas os bairros residenciais de Lisboa, mas sim os bairros de Urmeira, Olival Basto, Pombais...Quinta do Silvade, Odivelas..." respondendo que “... os bairros arrasados encontravam-se em zonas baixas, circundadas de colinas, facilmente inundáveis, construídos de tábuas e latas...". Interessante também é a análise feita aos fatores de risco que identificam na mesma edição da seguinte forma: “... desde há muito que se clama contra o assoreamento dos rios, contra a falta de diques. Desde há muito que se protesta contra os fenómenos de erosão... Nem a mais pequena verba para a regularização das águas do Tejo... Pergunta: ignorava porventura o Governo a insuficiência e o estado da rede de esgotos na cidade de Lisboa, onde desde há muito existem zonas mártires de inundações. Não sabia o governo que essas zonas se alagam quando de chuvadas normais?" (Avante!, 12/1967, no 386).

\section{As campanhas de solidariedade e voluntariado social}

As inundações na região de Lisboa produziram avultados danos materiais e produziram uma imediata necessidade de mantimentos e remédios, de água e comunicações. Os seus efeitos foram atenuados pela ação organizada de setores da população, pelos soldados, cantoneiros e trabalhadores voltados à ingente e pesada tarefa de recuperar casas e limpar ruas da lama invasora (COSTA et al. 2014). Enquanto isso, chegavam medicamentos, agasalhos, alimentos e assistência sanitária, numa cena que se repetia por toda a área atingida (PAVIANI 1968).

Num ambiente de comoção geral, promovem-se em diferentes localidades peditórios, espetáculos e subscrições, visando recolher fundos para apoio aos sinistrados. Os estudantes, por exemplo, participam nas ações de auxílio que se efetuam no terreno, desdobrando-se em tarefas como a vacinação em massa contra a febre tifoide, a desobstrução de casas e ruas e a instrução sanitária das populações. A dimensão real do desastre e das condições de vida de uma vasta camada da sociedade portuguesa não ultrapassou a espessa cortina da censura, mas muitos estudantes universitários, que agiram de 
forma imediata para prestar ajuda, tiveram a possibilidade de entrar em contacto com a situação verdadeira. A participação de quase seis mil estudantes nas atividades de socorro não agradou às autoridades, que intervieram procurando dificultar e desacreditar este trabalho, também através da intervenção da PSP (Polícia de Segurança Pública). A participação de estudantes, apesar do sentimento de impotência face à dimensão da tragédia para a qual não estavam preparados, permitiu criticar as deficiências dos serviços sanitários e sociais do Governo, revelar a eficácia de organismos democraticamente organizados (como a rede de apoio estudantil) e denunciar as miseráveis condições de vida em várias zonas do país (DUARTE 1997; CARDINA 2008; ACCORNERO 2009).

Em Lisboa, a planificação das ações de socorro encontrou-se a cargo de uma Comissão Coordenadora Central, instalada na associação de estudantes do Instituto Superior Técnico, da qual fazem parte a Juventude Universitária Católica e várias associações de estudantes. Tendo durado cerca de duas semanas, abrangeram centenas de estudantes. Em cada jornada, divulgavam o sucedido à população que pouco sabia da dimensão da catástrofe, dada a ação da censura. Merece especial realce nesta divulgação o periódico Solidariedade Estudantil, que chegou a ter uma tiragem de 10.000 exemplares e se esgotou numa manhã (OLIVEIRA 2013). Este Boletim foi distribuído pelo «Secretariado Coordenador da Informação e Propaganda» (SCIP) das Associações de Estudantes de Lisboa e publicado a propósito da ação, procurando relatar o trabalho efetuado pelos estudantes e apresentar um conjunto de comentários críticos ao acontecido, equacionando-o em termos de uma análise das causas (e das consequências) sociais da tragédia (FERREIRA 1969).

No Porto, grupos estudantis organizam uma recolha de donativos a favor dos atingidos. De Coimbra partem alguns estudantes, sobretudo de Medicina, que integram brigadas de auxílio aos sinistrados. Chegados ao local, o voluntarismo terá sido matizado por certa impotência em fazer face à dimensão da tragédia, para a qual não estavam preparados a nível técnico. O jornal Comércio do Funchal elenca as tarefas desenvolvidas por estes estudantes no dia 17 de Dezembro de 1967: “...vacinação em massa contra a febre tifoide; instalação de postos clínicos; informações sanitárias à população, separação das populações em maior risco de contraírem febre tifoide; inquérito profilático às populações, ideia que também teve a aprovação da DGS; velas noturnas para casos urgentes; organização de creches com os devidos cuidados médicos e de puericultura... Apesar disso, a participação dos estudantes nestas ações possibilitou, num mesmo lance, criticar a impreparação e desorganização dos organismos sociais e sanitários do Governo, enaltecer a capacidade realizadora de Organizações Democráticas e Livres e, ainda, denunciar a existência de condições de vida miseráveis em várias localidades do país (Comércio do Funchal, 17/12/1967, no 1964).

Os testemunhos dos estudantes relatados pelo Comércio do Funchal revelam esta mesma denúncia: “A nossa participação carateriza-se, ao contrário da oferecida por outras entidades, pelo conhecimento exato e desmistificado da extensão do desastre, que não atribuímos à imprevisibilidade das chuvas, à conformação do terreno ou quaisquer condições naturais inimputáveis e de acaso, mas sim a condições sociais, económicas e administrativas bem concretas. Como pode isso acontecer, sem sequer se tenha verificado o rebentamento de diques ou barragens, ventos ciclónicos, desmoronamentos em série...? A resposta apresenta-nos agora, na sua realidade indesmentível: acentuadas condições de desenvolvimento em que viviam as populações atingidas sem os mais elementares requisitos de sanidade e segurança; ausência quase total de sistemas 
de segurança e socorro, prevenção de epidemias, redes de escoamento de águas, condições de estabilidade de terrenos, defesa contra aluimentos de terrenos, inundações; previdência social precariamente montada, quase inexistente, de tal forma que não foi possível organizar desde a primeira hora o serviço complexo do auxílio às vítimas, deixando ao sabor da iniciativa individual ou de organizações, mais ou menos oficiais..." (Ibidem).

Por sua vez o Ministério de Interior tornou uma nota oficiosa a propósito das trágicas ocorrências em que destaca a mobilização de "... todos os meios disponíveis, incluindo os do Exército, da Marinha, da Força Aérea e de outras instituições como a Cruz Vermelha, a Cáritas, o Movimento Nacional Feminino, a Legião Portuguesa, os escuteiros, a Misericórdia de Lisboa... aproveitando todas as boas vontades, designadamente as de estudantes..." (Diário de Lisboa), versão, aliás, seguida e verificada no Seventh report da Agency for International Development (USAID 1967): "Action taken by the Government of Portugal and National and local organizations. There was immediate action on the part of the government of Portugal to bring assistance to the disaster victims. The military and Portuguese Red Cross assisted. Ambulance services of the Portuguese Red Cross were quickly at the scene of the disaster and the Society established a camp near Ulmeira, one of the regions won't hit. The Public Health Department initiated a program of vaccination and inoculation to prevent epidemics and was assisted in this by the Red Cross" (USAID 1967).

Esta campanha marcou, para muitos estudantes, a rutura definitiva com o Estado Novo. Rita Veiga, evocando em 1997 a sua participação nesta jornada, fala da lama como uma força maligna que deixava atrás de si um cheiro ácido a humores orgânicos como se tivesse conservado em si a miséria das barracas que destruíra. A lógica corporativa do regime não podia tolerar que organizações não enquadradas oficialmente e com laivos de hostilidade relativamente ao regime, aparecessem como mais empenhadas do que o governo na assistência ao desastre. Ao mesmo tempo, a intervenção estudantil no auxílio à catástrofe serviu, assim, como um importante motor de politização das jovens gerações que, a partir das universidades, vinham ensaiando modos de contestação menos elitistas e mais aguerridos. Longe das preocupações elitistas de outrora, os estudantes ensaiavam já uma efetiva abertura à sociedade, efetuada num liame de contornos marxizantes, através do encontro com as faixas mais pauperizadas da população. De qualquer forma, o aspecto mais importante com respeito a estes episódios, foi a difusão e extensão da iniciativa e do estímulo à participação (CARDINA 2008b: 65-66).

\section{A ação da censura}

Apesar de num primeiro momento se permitirem notícias sobre o assunto, a ação censória agiu para evitar leituras políticas da catástrofe e evitar que a comoção geral instalada adquirisse laivos críticos, como é possível perceber em alguns exemplos referidos por César Príncipe. No dia 27 de Novembro, um telegrama da Direcção da Censura enviou a seguinte informação às delegações locais: "Gravuras da tragédia: é conveniente ir atenuando a história. Urnas e coisas semelhantes não adianta nada e é chocante. É altura de acabar com isso. É altura de pôr os títulos mais pequenos". Dois dias depois, a 29 de Novembro, determinava-se: "Inundações: os títulos não podem exceder a largura de $1 / 2$ página e vão à censura. Não falar no mau cheiro dos cadáveres. Atividades beneméritas de estudantes - Cortar" Dias mais tarde eram emitidas novas orientações pelo mesmo órgão como mostram os seguintes exemplos: "Deliberação do Senado universitário de Coimbra acerca do auxílio a prestar às vítimas das enxurradas. Cortar. A notícia só pode sair nos Jornais de Coimbra" (PRÍNCIPE 1979). 
Lembre-se que, ao mesmo tempo que tentaram ocultar a divulgação atualizada do número de mortos da tragédia das cheias, as autoridades portuguesas acusaram a imprensa estrangeira de notícias tendenciosas acerca da forma como o governo havia atuado. Pelo mesmo motivo, e como refere Irene Pimentel, a Polícia Internacional e de Defesa do Estado (PIDE) também interrogou então o correspondente da United Press International, Edouard Khavessian, acerca de uma informação dada por essa agência, sobre protestos estudantis contra a atuação do governo português em relação aos socorros prestados à população (PIMENTEL 2007: 48-49).

\section{CONCLUSÕES}

As cheias ocorridas na região da Grande Lisboa, na noite de 25 para 26 de Novembro de 1967, constituem ainda hoje um objeto pouco estudado. Permanece por contabilizar com rigor o número de vítimas mortais e a dimensão da tragédia que exigiria uma maior visibilidade do episódio no espaço público. Esta apresentação procurou resgatar o acontecimento, focalizando nos seus impactes enquanto um evento pluviométrico extremo, assim como algumas dinâmicas políticas e sociais que desencadeou. Num tempo em que Portugal vivia sob uma ditadura que intervinha através da censura na imprensa e que não permitia partidos políticos para além do partido único (União Nacional), as cheias inscreveram-se ainda assim no debate político, motivando posicionamentos distintos (COSTA et al. 2014). O regime, e os órgãos em sintonia com a ditadura, procuraram enquadrar o ocorrido na categoria de desastre natural, vincando a inevitabilidade e a cadeia de solidariedade estabelecida; as estruturas oposicionistas colocaram na tónica nas condições sociais que fizeram com que as fortes chuvadas se transformassem num desastre humano e, portanto, de certo modo evitável nas suas consequências.

\section{REFERENCIAS}

ACCORNERO, GUYA, 2009. Efervescência Estudantil. Estudantes, acção contenciosa e processo político no final do Estado Novo (1956-1974). Dissertação de Doutoramento em Ciências Sociais, Especialidade de Sociologia Histórica, Universidade de Lisboa, Instituto de Ciências Sociais, Lisboa, 350 p.

AMARAL, I., 1968. As inundações de 25/26 de Novembro de 1967 na região de Lisboa. Finisterra, Revista Portuguesa de Geografia, 3(5): 79-84.

CARDINA, MIGUEL, 2008a. Memórias incómodas e rasura do tempo: Movimentos estudantis e praxe académica no declínio do Estado Novo. Revista Crítica de Ciências Sociais, 81: 111-131.

CARDINA, MIGUEL, 2008B. A Tradição da Contestação. Resistência Estudantil em Coimbra no Marcelismo. Coimbra: Angelus Novus.

COSTA, F. S., M. CARDINA \& A. A. B. VIEIRA, 2014. Inundações na região de Lisboa (1967). Um olhar sobre o impacto político e social. Actas do VIII SLAGF Simposio Latinoamericano de Geografia Fisica, IV SIAGF Simposio Iberoamericano de Geografia Fisica, Facultad de Arquitectura y Urbanismo, Universidad do Chile, Santiago, Chile: 1263-1271.

COUTINHO, M.A., 1984. Intervenção na bacia e na rede hidrográfica. Seminário sobre as cheias de Novembro de 1983, publicação 3/84, I.S.T.: 3.1-3.33.

DUARTE, M. B., 1997. Foi apenas um começo. A crise académica de 1969 na história do movimento estudantil dos anos Sessenta e da luta contra o Estado Novo. Tese de mestrado, Universidade Nova de Lisboa, Faculdade de Ciências Sociais e Humanas. 
DUARTE A., B. BORGES, C. RAMOS, P. PEDRO \& R. PAIXÃO, 2007. Cheias rápidas em áreas urbanas e sua percepção: o caso da Bacia da $\mathrm{R}^{\mathrm{a}}$. de Odivelas. Apontamentos de Geografia, Série de Investigação $\mathrm{N}^{0}$ 21, Centro de Estudos Geográficos, 14p.

FERREIRA, V., 1969. Inventário analítico da imprensa estudantil portuguesa em 19451967. Análise Social, 7 (25-26): 223-281.

FERREIRA, A. B., J. L. ZÊZERE \& M. L. RODRIGUES, 1987. Instabilité des versants dans la region au nord de Lisbonne. Essai de cartographie géomorphologique. Finisterra, Revista de Geografia Portuguesa, 22 (44): 227-246.

JORNAL AVANTE!, 1967.

JORNAL COMÉRCIO DO FUNCHAL, 1967.

JORNAL DIÁRIO DE LISBOA, 19671968.

JORNAL DIÁRIO DE NOTÍCIAS, 1967.

JORNAL SÉCULO ILUSTRADO, 1967.

JORNAL ESTUDANTIL, 1967.

SOLIDARIEDADE

LEAL, M. H. A., 2011. As cheias rápidas em bacias hidrográficas da AML Norte: factores condicionantes e desencadeantes. Dissertação de Mestrado em Geografia Física e Ordenamento do Território, Universidade de Lisboa, IGOT.

PIMENTEL, IRENE FLUNSER, 2007. A Censura, In Madeira J., Pimentel I. F., Farinha 1. (2007). Vítimas de Salazar. Estado Novo e violência política, Lisboa, Esfera dos Livros, 452 p.
PAVIANI, A., 1968. Alenquer, Aspectos Geográficos de uma Vila Portuguesa. Finisterra, 5: 32-78.

PRÍNCIPE, CÉSAR, 1979. Os Segredos da Censura. Lisboa Caminho (Ed).

OLIVEIRA, L. T., 2013. O ativismo estudantil no IST (1945-80). In Branco, Jorge Freitas, ed. - Visões do Técnico, no Centenário 1911-2011, Lisboa, ISCTEIUL: 307-370.

OLIVEIRA, P. E. \& CATARINA RAMOS, 2002. "Inundações na cidade de Lisboa durante o século XX e seus factores agravantes". Finisterra, Revista de Geografia Portuguesa, 37 (74): 33-54.

RAMOS C. \& E. REIS, 2001. As cheias no sul de Portugal em diferentes tipos de bacias hidrográficas. Finisterra, Revista de Geografia Portuguesa, 36(71): 61-82.

RODRIGUES, C., R.C.E. GUIMARÃES \& M. MOREIRA, 2011. Apontamentos para as aulas de Hidrologia - Departamento de Engenharia Rural. Universidade de Évora.

REBELO, F., 2008. Um novo olha sobre os riscos? O exemplo das cheias rápidas (flash floods) em domínio mediterrâneo. Territorium, 15: 7-14.

REBELO, F., 2010. Geografia Física e Riscos Naturais. Imprensa da Universidade de Coimbra, 215 p. Seaman, J., Leivesley, S., Hogg, C. (1989). Epidemiologia de desastres naturales. Fonte: México, D.F; Harla; $161 \mathrm{p}$.

SEQUEIRA, M.N. \& L.F. CASTRO, 1987. Riscos e catástrofes no domínio dos recursos hídricos. Avaliação dos prejuízos causados pelas cheias e análise custobenefício de execução de obras destinadas a 
evitá-los: a lição do município de Cascais. II Simpósio Luso-Brasileiro sobre Hidráulica e Recursos Hídricos, A.P.R.H., Lisboa.

SIMÕES, J., J. F. AZEVEDO \& J. M. PALMEIRO, 1969. Some aspects of the Weil's disease epidemiology based on a recent epidemic after a flood in Lisbon (1967). Anais Esc. Nac. Saúde Pública e de Medicina Tropical, 3: 19.32.

TRIGO R. M., J. L. ZÊZERE, M. L. RODRIGUES \& I. F. TRIGO, 2005. The Influence of the North Atlantic Oscillation on Rainfall Triggering of Landslides near Lisbon. Natural Hazards, 36: 331-354.

USAID, 1967. Disaster. Foreign emergency relief. Seventh report, July - December, Agency for International Development. $112 p$.
ZÊZERE, J. L., 2001. Distribuição e ritmo dos movimentos de vertente na região a norte de Lisboa. Relatório $\mathrm{n}^{\mathrm{o}} 38$, Área de Geografia Física e Ambiente, Lisboa, CEG, $167 \mathrm{p}$.

ZÊZERE J. L., R. M. TRIGO \& I. F. TRIGO, 2005. Shallow and deep landslides induced by rainfall in the Lisbon region (Portugal): assessment of relationships with the North Atlantic Oscillation. Natural Hazards and Earth System Sciences, 5: 331344.

ZÊZERE, J. L. \& M. L. RODRIGUES, 2002. Rainfall Thresholds for Landsliding in Lisbon Area (Portugal). Rybar, Stemberk \& Wagner (Eds.), Landslides, A.A. Balkema, Lisse: 333-338. 